\title{
Designed ecosystem services: application of ecological principles in wastewater treatment engineering
}

\author{
David W Graham ${ }^{1}$ and Val H Smith ${ }^{2}$
}

Wastewater treatment engineering and ecology have complementary goals and need to interact much more closely. Wastewater engineers and ecologists share strong interests in the structure and function of biological communities, yet rarely engage in extensive interdisciplinary dialogue. Wastewater (bioprocess) engineers focus on solving practical environmental problems and typically do not work forward from ecological principles to test specific theories. Ecologists, on the other hand, have focused primarily on the collection and analysis of data in order to test specific scientific hypotheses; only recently have they emphasized ecological applications as well. Wastewater engineers should use the fundamentals of ecological theory to help guide future system design and ecologists should view engineered biosystems as valuable new platforms for ecological research.

Front Ecol Environ 2004; 2(4): 199-206

B oth ecology and environmental engineering, especially biological waste treatment engineering, seek to solve human-related and environmental problems. Although the two disciplines clearly have complementary goals, their history and perspectives have historically been quite different, limiting direct dialogue between classical ecologists and engineers. The term "engineering", for example, is missing from the index of Krebs (2001) and Stiling (2002), two widely used ecology texts that emphasize both theory and application. Similarly, neither Bitton's textbook on wastewater microbiology (1999), nor Gaudy and Gaudy's (2001) treatise on bioenvironmental engineering, contain the word "ecology" in their indices. This lack of discussion has left the full potential of both disciplines unrealized. It is time for ecologists and bioprocess engineers to work together more closely on key environmental issues; both will benefit from such new synergistic interactions.

In a nutshell:

- Current biological waste treatment practices rely heavily on practical experience as the basis for biological process design and operation

- Concerted efforts to more formally incorporate modern ecological principles into engineering microbiology will place waste treatment onto a much firmer theoretical footing

- Ecological theory can be used to inform, guide, and enhance engineering biology practice

- Engineered biosystems can provide excellent models for basic ecological research

${ }^{1}$ Department of Civil, Environmental, and Architectural Engineering, University of Kansas, Laurence, KS 66045; ${ }^{2}$ Department of Ecology and Evolutionary Biology, University of Kansas, Lawrence, KS 66045 (vsmith@ku.edu)

Ecologists' input is needed to help solve engineering problems; specifically, knowledge of ecological principles could improve the prediction of process behavior and system performance. Conversely, biological waste treatment processes should interest ecologists, because such engineered ecosystems are deliberately designed to provide specific ecosystem services. These systems could act as excellent models for ecological research, broadening understanding of microbial ecosystems and generating new insights in basic ecology.

\section{Wastewater engineering - a historical example}

Microbiological solutions have been used to address environmental problems for thousands of years. Evidence indicates that as early as $3000 \mathrm{BC}$, Mesopotamians near modern-day Baghdad had sewage processing systems to treat solid and liquid domestic wastes. The Mesopotamian treatment systems were easy to construct and performed their desired function most of the time, although no major efforts were made beyond simple empirical modifications to make these processes more effective. Many processes for waste management were subsequently developed elsewhere in the world (Figure 1 ), but only recently has the scientific basis of most waste management processes been studied with any rigor.

As local human population densities increased due to more centralized agricultural practices (Diamond 1997), previously effective treatment strategies became overwhelmed by the sheer mass of waste generated in large population centers. The need for more sophisticated waste management methods quickly became apparent. Sir John Ruskin, a famous architect of his day, predicted that the beauty of 19th century Venice would soon be lost due to 

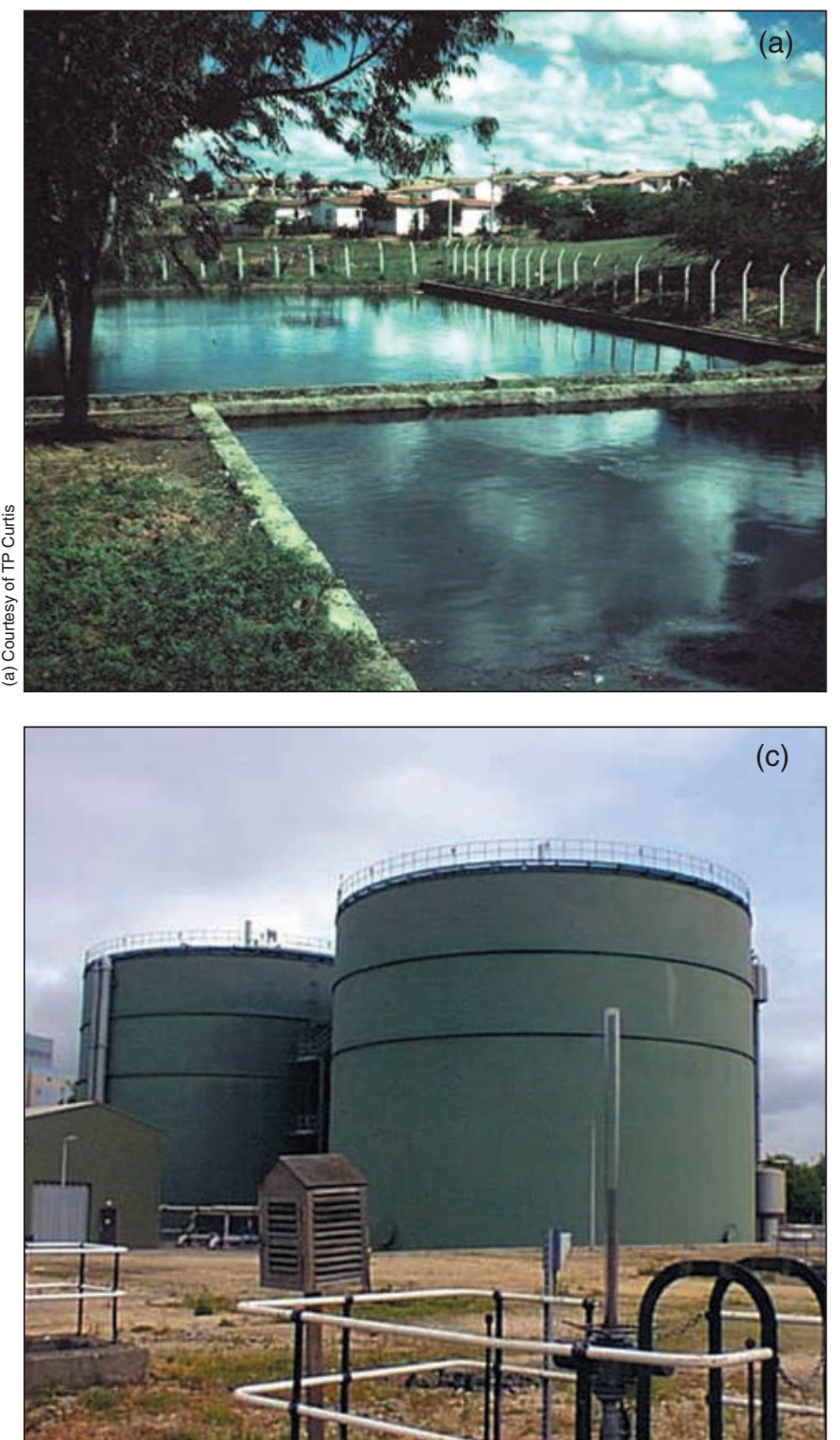

Figure 1. Examples of wastewater treatment processes around the world. (a) Sewage stabilization ponds in Brazil. (b) Complex lagoon and stabilization pond treatment system in France. (c) Anaerobic digesters in England. (d) Trickling bio-filter bed (viewed from the side) in Canada. (e) Conventional wastewater treatment plant digestion in the US, including primary treatment, secondary treatment, secondary clarifiers, and solids.

poorly considered waste handling practices (Wheeler 1995) - disease epidemics were rampant, surface waters were badly polluted, and buildings were beginning to decay. Although the chemistry of waste management was being studied quite extensively at the time, the biological root of many of the problems was largely unknown.

Two events later helped to improve the technological basis for waste management practices. First, Louis Pasteur, Ferdinand Cohn, and then Robert Koch demonstrated, through improved microscopy and shrewd experimentation, that microorganisms were ubiquitous in nature, and it became clear that microbes play major roles in both disease and other environmental processes (de Kruif 1926).
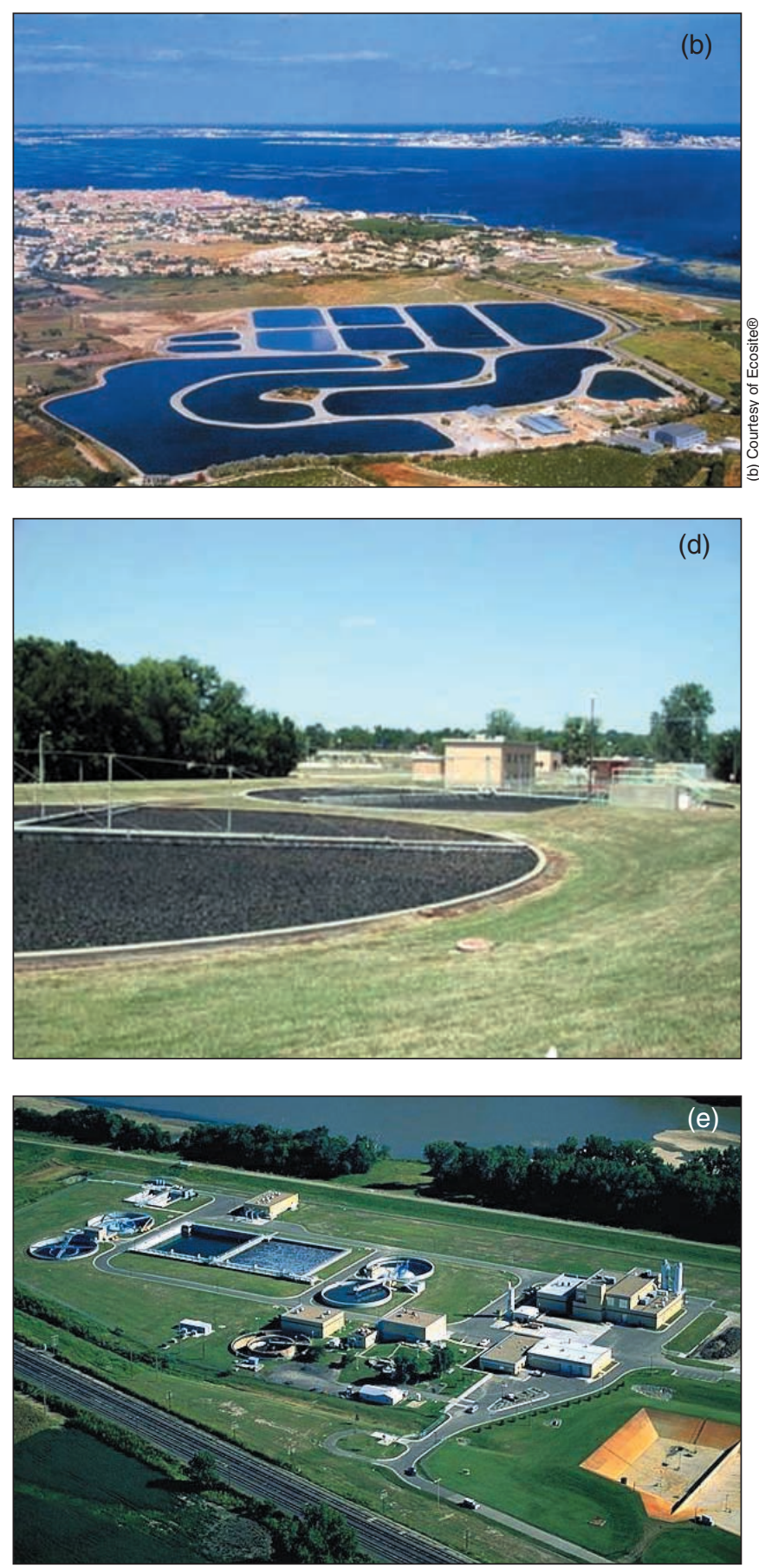

Second, sanitary engineers found that if they suspended domestic wastes in liquid, provided additional aeration, and mixed the suspension aggressively, waste degradation rates were accelerated such that even highly concentrated wastes could be efficiently transformed into relatively benign end products (ISP 1954).

As wastewater treatment methods continued to develop, it became apparent that these processes depended largely upon the activity of diverse microbial communities, which functionally consumed the wastes. As refinements evolved, both engineered fixed-film processes (involving microbial growth on the surfaces of particulate substrates) and suspended-culture processes 
(involving microbial growth in open water columns) were developed (Figure 1). Waste treatment is now the world's most common "biotechnology" (Wagner et al. 2002); in the US alone, over 15000 wastewater treatment facilities collectively process 100 billion L of wastewater per day (Bitton 1999).

Despite the massive scale of the wastewater treatment industry, only modest advances have occurred in our basic understanding of these biological treatment processes during the past century or so. In 1912, environmental chemists Arden and Lockett noted the importance of activated solids (ie microorganisms) and aeration in treatment processes. It was not until the 1950s, however, that both biochemical and ecological factors were recognized as fundamental to effective process performance (ISP 1954). Early leaders in this research were Ross McKinney and Perry McCarty. McKinney developed a

deep, almost intuitive, understanding of the microbial ecology of waste treatment systems (McKinney 1962), whereas McCarty attempted to quantify treatment process performance by developing general predictive equations (based upon Monod kinetics and the assumption that biological treatment processes operate at a steady state) that could be used by treatment system designers (Lawrence and McCarty 1970).

Although the efforts of McKinney, McCarty, and others (eg Downing et al. 1964) were central to improving understanding of engineered biological processes, they predate many recent advances in ecology, molecular biology, and mathematical biology. It is time to reassess the design and operation of these biological systems in light of this new knowledge. Developments in complexity theory, biogeography, molecular biology, and computational methods, when considered within the context of engineering biology, may provide solutions to many unsolved problems in biological waste treatment engineering (Curtis et al. 2003).

\section{Basic engineering elements of wastewater treatment}

Figure 2 provides a basic schematic for most conventional wastewater treatment systems (Metcalf and Eddy 2003). Wastewater treatment consists of four general steps, two of which are strongly influenced by ecological factors: (1) primary treatment, which removes large solids from the incoming wastewater stream (eg coarse screens, grit cham- bers, and/or primary sedimentation basins); (2) secondary treatment (activated sludge systems or fixed-film biofilters or both) that primarily removes dissolved organic matter; (3) secondary clarification that settles, collects, and recycles solids produced during secondary treatment; and (4) solids digestion (anaerobic or aerobic digesters) that reduces biosolids trapped or generated in the earlier treatment steps. Although most community treatment systems in North America and Europe include these basic steps, actual designs vary from place to place. Some treatment facilities also include tertiary treatment aimed at nitrogen $(\mathrm{N})$, phosphorus $(\mathrm{P})$, and/or residual organic carbon $(\mathrm{C})$ removal from secondary treatment effluents. Of the treatment steps above, secondary and tertiary treatment and solids digestion are the most dependent on the actions of mixed microbial communities.

These various processes follow one of three general physical designs. The first and most common system is called "activated sludge", which has been used for the treatment of organic matter-rich wastewaters since about 1910 (Martin 1927). It employs suspensions of mixed microbial cultures grown in bioreactors (Figure 1e) to treat the wastes. The goal of an activated sludge system is to oxidize biodegradable organic matter, transforming it into microbial biomass and $\mathrm{CO}_{2}$ in an aerated tank, then to flocculate and separate the newly-formed biosolids in a downstream clarifier (Bitton 1999). In the flocculation process bacteria and other suspended particles clump together into larger masses called "floc".

The second treatment strategy employs fixed-film pro- 
cesses in which the wastewater trickles slowly through porous media (usually composed of sands, gravels, stones, or other large particulates). Biofilms then form on the porous media as microbes colonize and adhere to the available surfaces, forming an attached biological community, often comprised of many different species of bacteria, fungi, and protozoa, which interacts with and purifies the waste stream (see Figure 1d). The third type of biological process design involves more natural treatment systems, such as stabilization ponds or wetlands (Figures 1a and $1 b)$. The common goal of most treatment strategies is (1) to reduce net biosolids production (or at least to promote internal solids digestion), while (2) maximizing organic C removal from the incoming liquid.

\section{Wastewater treatment systems from an ecological perspective}

The abundance and species composition of resident microbial communities and the quality of the final effluent produced by individual wastewater treatment systems can vary, based on differences in the physical designs and operating conditions of the systems. Thoughtful application of ecological principles would enhance wastewater treatment plant design and operation by providing a more objective framework for understanding the factors that influence the structure and function of the plants' microbial communities. These engineered biosystems, in turn, offer exciting new opportunities for the development and testing of ecological principles.

Evidence suggests, for example, that wastewater treatment plants behave like complex systems with respect to their biology (Graham and Curtis 2002; Saikaly and

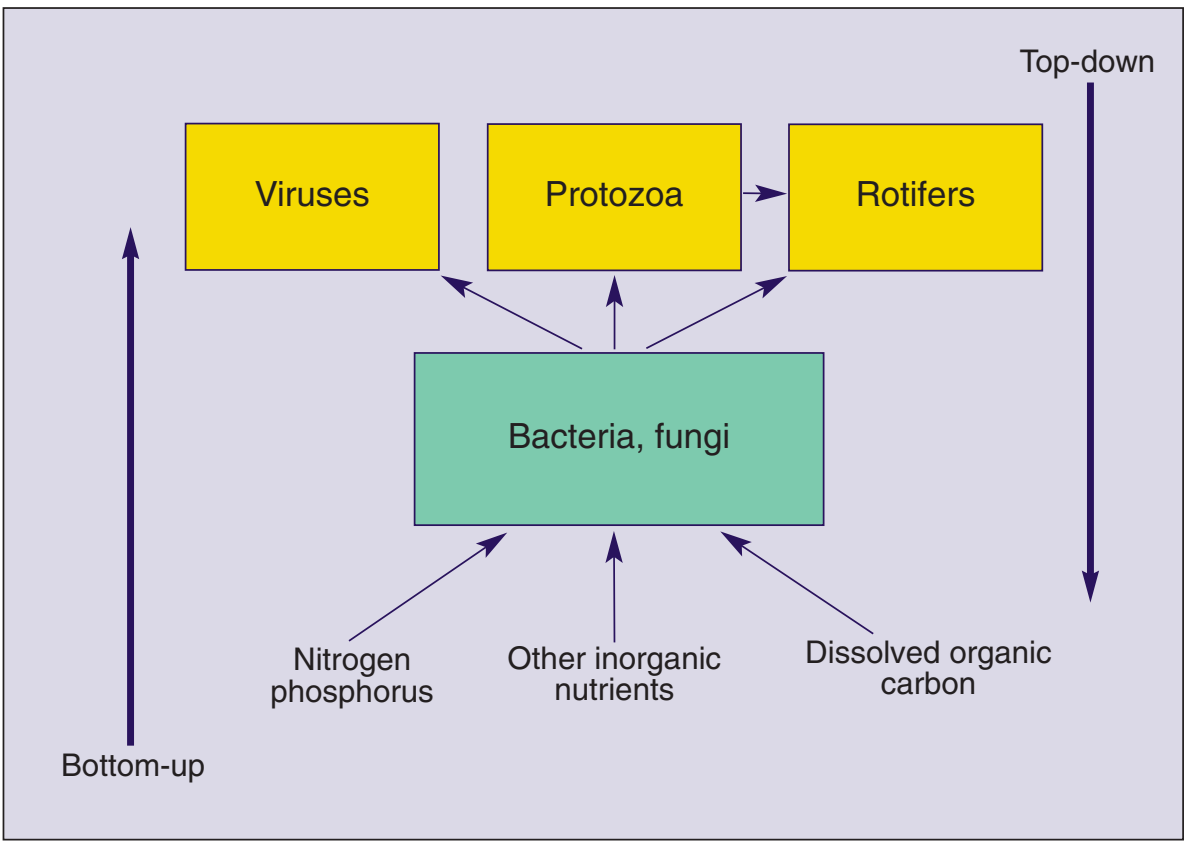

Figure 3. Generalized microbial food web in an activated sludge floc. The microbial food web is influenced by both bottom-up (resource-supply driven) and top-down (predationdriven) forces.
Oerther in press). As with other aquatic ecosystems (eg Gasol et al. 2002), biological treatment processes are best viewed as exhibiting simultaneous bottom-up (resource supply-driven) and top-down (food web structure-driven) control of ecosystem structure and function (Figure 3). The incoming wastewater stream supplies resources to the treatment system in the form of both dissolved and particulate nutrients. These resources drive the growth and reproduction of a diverse microbial community, which is then subjected to grazing losses by protozoa and other consumers, as well as to other sources of cell mortality, such as viral infection. The resulting biosolids are physically removed from the system by settling or filtration. The size and species composition of the microbial community are thus regulated simultaneously by the supply rate and composition of the wastewater feed, by predation, and by complex interactions between the resident organisms.

The food webs of most natural aquatic ecosystems are typically depicted as a classic food chain composed of easily visible organisms, such as algae, zooplankton, fish, and other large consumers. Also present, but less visible to the unassisted eye, is a diverse community of bacteria, archaea, fungi, viruses, and protozoa, known as the "microbial loop" (Azam et al. 1983). In natural ecosystems, the microbial loop works alongside, or is embedded within, the classical food chain. In wastewater biosystems, however, the microbial loop is dominant and is responsible for essentially all of the waste treatment processes.

With the advent of new molecular biological techniques, biological treatment systems are ideal vehicles for studying the microbial loop. These treatment systems are innately complex and diverse, but they are also physically contained, allowing a nearly complete characterization of the entire ecosystem. Resident microorganisms have very short generation times in these nutritionally rich environments, and comprehensive ecological studies can be performed over relatively short time frames. Moreover, a diverse set of consumers is present in the form of viruses, protozoa, rotifers, and in some cases, nematodes and microcrustacea. This food web is very dynamic, and ecological succession often occurs within the consumer community during treatment (Figure 4).

Although most waste treatment processes are reliable and fairly predictable, these processes can malfunction, and bioprocess engineers wish to minimize these system failures. Many of the critical problems that arise during biological waste treatment can be attributed to variations in the relative abundance of 
key microbial species (Figure 5; Panel 1). Understanding these variations in community composition (which were previously considered unpredictable) is one of the key engineering problems that may be solved through a more complete understanding of the quantitative ecology of wastewater treatment processes. Desirable, floc-forming bacteria, for example, have been viewed as r-strategists, which are characterized by very rapid population growth rates, but, in general, are poor resource competitors. In contrast, nuisance filamentous bacteria associated with engineering problems such as foaming or bulking have been viewed as $\mathrm{K}$-strategists, which, in general, have slower population growth rates, but are more effective competitors, making more efficient use of available growth-limiting resources (Morin 1999). However, the validity of this ecological distinction is unclear because few quantitative measurements of the respective growth kinetics of floc-formers versus nuisance filamentous species have been made in real systems (Seviour 1998).

\section{Tertiary treatment: the ecology of advanced nutrient removal}

The secondary wastewater treatment systems discussed above were first designed primarily to remove organic $\mathrm{C}$ from incoming wastewater streams. Tertiary treatment stages are now also included in many wastewater treatment facilities to provide more complete pollutant removal. The addition of advanced treatment has been driven mainly by the need to manage freshwater and marine eutrophication (Welch and Lindell 1992; Howarth et al. 2000), and many countries are imposing more stringent criteria for $\mathrm{N}$ and $\mathrm{P}$ control. From a microbial perspective, the $\mathrm{N}$ removal is much better understood than the $\mathrm{P}$ removal, although both processes can be quite unreliable.

This unpredictability in ecosystem function is related to a poor understanding of the ecology of the microorganisms responsible for the associated biochemical reactions. Purkhold et al. (2000) found, for example, that few of the nitrifying bacteria classically studied in the laboratory were present in full-scale nitrification systems. Their observations, made using molecular biological techniques, suggest that laboratory-scale results may not always be readily transferable to actual waste treatment systems.

Although recent advances in molecular techniques have improved our understanding of the microbiology of nitrification and denitrification treatment processes (eg Rowan et al. 2003), much can still be learned from applying more detailed information from microbial ecology during engineering process design. Improving this ecological knowledge base should be a major goal for engineering microbiology, especially for those involved in biological $\mathrm{P}$ removal processes (Blackall et al. 2002). From an ecologist's perspective, the study of engineered nutrient removal is an ideal vehicle for the application of new techniques from the field of ecological stoichiometry (Sterner and Elser 2002).

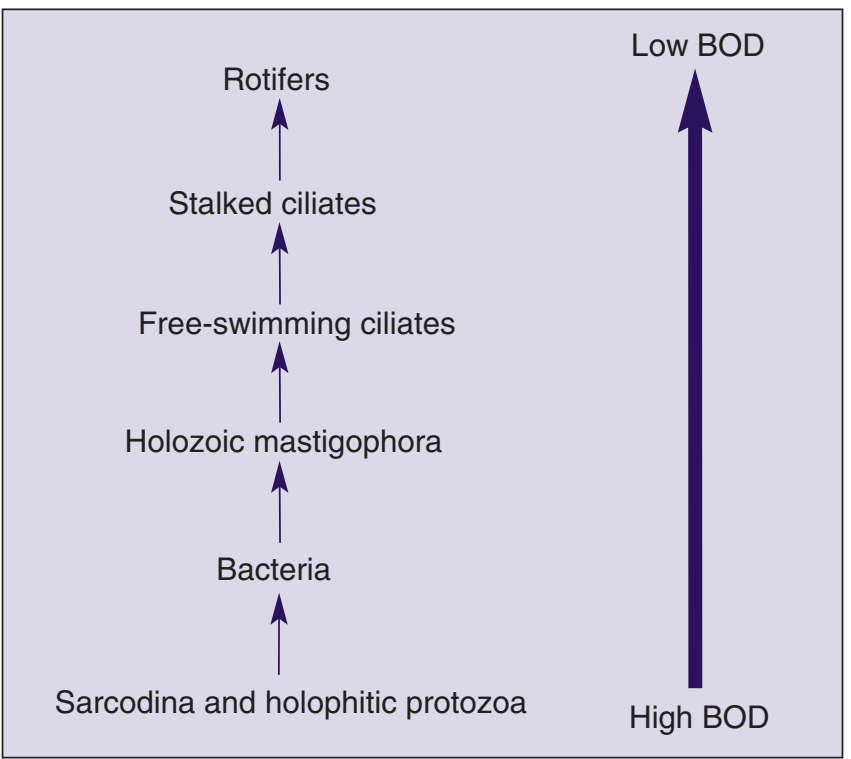

Figure 4. Ecological succession of microorganisms in activated sludge. Consumer species composition changes dramatically along a gradient of Biological Oxygen Demand (BOD) (adapted from Figure 8.9 in Bitton 1999).

\section{Other valuable ideas from ecology}

Both top-down and bottom-up processes (Figure 3) should strongly influence nutrient dynamics during biological waste treatment (Glibert 1998). Predator-prey interactions are strong in microbial communities (Thingstad et al. 1999; Langenheder and Jürgens 2001; Sherr and Sherr 2002), and may be important regulators of key treatment processes. Ward and Graham (1997) found, for example, that the survival of putative

Panel 1. Examples of wastewater treatment problems associated with variations in microbial community structure

\section{Biosolids removal problems}

Conditions in which biosolids do not settle properly in the clarifier following secondary treatment. Variations in settling behavior (dispersed growth, non-filamentous bulking, pinpoint flocs, rising sludge, filamentous bulking, foaming, and scum formation) are often correlated with shifts in dominance among resident microflora, resulting in microbial floc structures or other conditions that are unfavorable for gravity separation.

\section{Biochemical removal problems}

Reductions in pollutant removal efficiency can occur due to the absence, extinction, or poor ecological success of microbial species that perform key activities in the microbial treatment community (eg the loss of a bacterial species responsible for nitrification).

\section{System stability problems}

Unacceptably high temporal variation in biosolids levels or reductions in final effluent quality. Such stability problems may result from chaotic or random shifts in microbial community structure resulting from predator-parasite-prey and other ecological interactions between viruses, protozoa, and bacteria, or from the vagaries of microbial dispersal into and out of the reactor. 

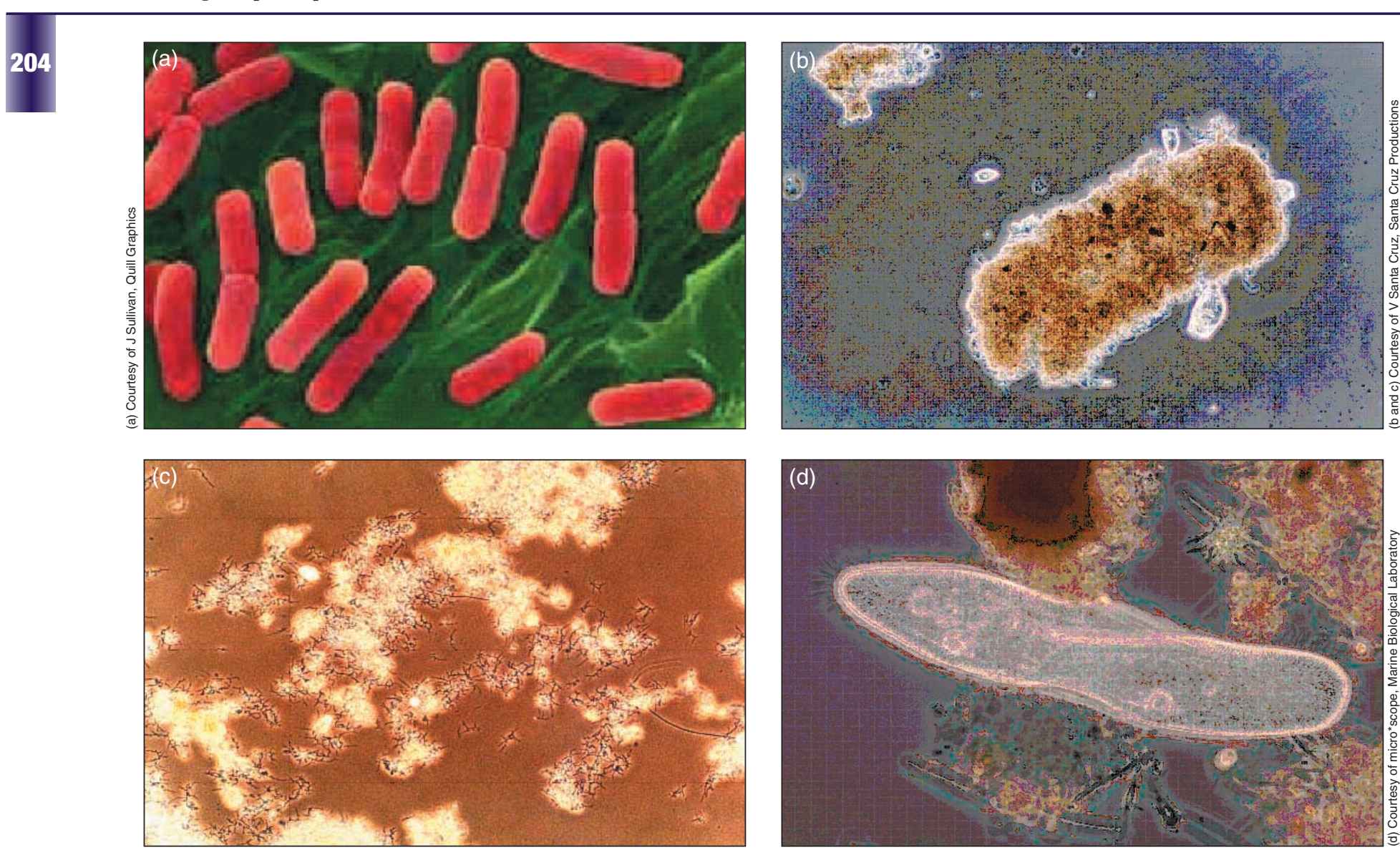

Figure 5. Microorganisms in biological wastewater treatment systems. (a) False color photomicrograph of Escherichia coli, a fecal coliform bacterium that interacts with activated sludge flocs. Each bacterium is $\sim 5$ microns in length. (b) A well-settling activated sludge floc. The largest aggregate is $\sim 0.5 \mathrm{~mm}$ in length. (c) Activated sludge flocs dominated by filamentous Nocardia bacteria settle poorly and contribute to poor waste treatment plant performance. Each short, threadlike Nocardia filament is 10-20 microns long. (d) Paramecium, a protozoan commonly found in activated sludge communities. This ciliate is about 200 microns in length.

pathogens in aerobic digesters may be linked to predator-prey dynamics. When eukaryotic predators (protozoa) were selectively inhibited in aerobic digesters, overall process performance (ie net percent solids reduction) changed relatively little, but effluent fecal coliform levels rose dramatically as operating temperature was increased. In addition, trade-offs between predator resistance and competitive ability can promote the coexistence of different types of microorganisms (Bohannan et al. 2002).

Improvements in our understanding of wastewater microbial food-web dynamics are much needed to enhance the effectiveness and stability of the secondary and tertiary treatment process. As evidenced by Kirchman (2002), research on the microbial loop has exploded since its initial description by Azam et al. (1983), and this knowledge base may provide valuable new insights into wastewater microbiology.

Important new insights can also be gained from theoretical ecology. Saikaly and Oerther (in press) have recently used methods similar to those of Huismann and Weissing $(1999,2000)$ to model microbial dynamics in secondary biological treatment processes. They found that the competitive exclusion principle did not necessarily apply to waste treatment systems because of the strong oscillatory dynamics of individual populations within the microbial community. Attempts are also being made to apply island biogeography and neutral ecological theories (MacArthur and Wilson 1967; MacArthur 1972; Bell 2000; Hubbell 2001) to microbial community assembly and biodiversity in waste treatment processes. The broadest observation from this new work is that microbial community assembly may be functionally random in many (but not all) treatment processes, and that it might be possible, using stochastic models alone, to predict and engineer, with statistical confidence, community biodiversity in many treatment processes. This possibility is becoming more likely as we develop a better fundamental understanding of global microbial biodiversity among organisms related to wastewater treatment and environmental functions (Curtis et al. 2002). Theoreticallybased perspectives may ultimately allow biological waste treatment community composition to become more predictable, which would be invaluable given the realities of complex system behavior (Curtis et al. 2003).

\section{Additional applications of ecological principles}

Ecological principles are now being applied to many realworld problems, ranging in scale from local ecosystems to 
Panel 2. Examples of biological engineering problems that might be solved through the imaginative application of theories and insights derived from community ecology

I. Optimal design and operation of outdoor wastewater treatment ponds and sewage lagoons

2. Optimal design and operation of wetlands used as pollutant filters

3. Optimal design and operation of bioreactors

4. Predicting and managing the responses of engineered biosystems to environmental and global change

5.Assembly and maintenance of stable biological communities in novel environments, including space vehicles and other offworld living environments

the entire biosphere (Lubchenko et al. 1991; Côté and Reynolds 2002). Nevertheless, the formal application of ecological theory and its perspectives is still in its infancy in engineering biology. We have highlighted the relevance of ecological principles to wastewater treatment because of the universal importance and widespread use of these processes throughout the world, but a number of additional engineering problems may be addressed through the application of ecological knowledge (Panel 2).

Efforts are being made to incorporate ecological theories into other engineering settings, including contaminant biodegradation. Smith et al. (1998) and Röling et al. (2002) used resource-ratio theory (Tilman 1982) as a theoretical framework in their attempts to predict the influence of resource supplies and supply ratios on the degradation rates of hydrocarbon contaminants. Although their work showed that resource-ratio theory was only partially useful for process description (it helped to predict ecosystem function, but not necessarily microbial community composition), it did show that a well-defined ecological framework could indeed be applied to engineering practice. In a very different study, Kildsgaard and Engesgaard (2001) observed dynamic oscillatory behavior (cyclic fingering) in community abundance and location in subsurface treatment systems, which was very reminiscent of oscillatory behavior seen in other dynamic ecosystems. It is also possible that the approaches espoused by Brown (1995) to macroecology and Turchin (2003) to population dynamics, may be used to help predict the behavior and performance of many different types of engineered systems. These approaches, if coupled with new and evolving molecular techniques such as real-time polymerase chain reaction, should allow the use of engineered systems to address basic issues in community assembly and population dynamics.

Researchers are also exploring the implications of neutral theories (Bell 2000; Hubbell 2001), which may be very relevant to the biodiversity of engineered ecosystems. A complementary approach termed "ecological engineering" has been developed, which focuses specifically on the design of human society as a component of its natural environment, for the benefit of both. Evolved from ideas promoted by HT Odum in the 1960s, this approach has experienced steady growth during the past 10 years (Mitsch 1997).

\section{Basic ecological studies using engineering systems: the future}

Concepts from ecology and mathematical biology can inform, guide, and enhance engineering practice. The essence of engineering is to adopt products from basic science, such as ecology, for practical purposes. It is also important that ecologists consider engineering systems as new vehicles for basic research.

Wastewater treatment units are ideal systems for basic studies of local and global biodiversity, biogeographical effects (bioreactors act like islands), population biology and non-linear dynamics, predator-prey interactions, and many other topics. It is of particular value to ecologists that in engineering systems reactions happen quickly and are physically contained; a great deal of data can thus be generated in a short time, thereby allowing model development and mathematical analyses of systems. Furthermore, if basic theoretical models are found to apply to engineered biological systems, which our early data suggest is the case, such models might be tested and refined using engineered biological systems and then translated back to other systems that contain larger organisms with slower growth rates. Engineers and ecologists will need to work even more closely together to solve environmental problems. Both disciplines will gain from such interactions, and a strong alliance between ecologists and engineers is essential to fully address critical local and global environmental challenges in the future.

\section{Acknowledgments}

This research was supported in part by National Science Foundation (NSF) Grant 98-16192 to MA Leibold and VH Smith, and NSF Grant EPS-9874732 to DW Graham, FJ Devlin, and J Kelly. The ideas presented in this paper benefited greatly from our interactions and discussions with participants of the NSF and State of Kansas sponsored symposium, Frontiers in Engineering Biology, held in December 2002 at the University of Kansas. We also thank Brendan Bohannan, Tom Curtis, Rick Devlin, Peter Engesgaard, Ian Head, Bob Holt, John Kelly, Peter Morin, Dan Oerther, Bill Sloan and Tat Ebihara. Table 2 was inspired by a table of ecological applications in Morin (1999).

\section{References}

Azam F, Fenchel T, Field JG, et al. 1983. The ecological role of water-column microbes in the sea. Mar Ecol-Prog Ser 10: 257-63.

Bell G. 2000. The distribution of abundance in neutral communities. Am Nat 155: 606-17.

Bitton G. 1999. Wastewater microbiology, 2nd ed. New York, NY: Wiley-Liss, Inc. 
Blackall LL, Crocetti GR, Saunders AM, and Bond PL. 2002. A review and update of the microbiology of enhanced biological phosphorus removal in wastewater treatment plants. Anton Leeuw Int J G 81: 681-91.

Bohannan BJM, Kerr B, Jessup CM, et al. 2002. Trade-offs and coexistence in microbial mesocosms. Anton Leeuw Int J G 81: 107-15.

Brown JH. 1995. Macroecology. Chicago, IL: University of Chicago Press.

Côté IM and Reynolds JD. 2002. Predictive ecology to the rescue? Science 298: 1181-82.

Curtis TP, Sloan WT, and Scannell JW. 2002. Estimating prokaryotic diversity and its limits. P Natl Acad Sci USA 99: 10494-99.

Curtis TP, Head IM, and Graham DW. 2003. Theoretical ecology in engineering biology. Environ Sci Technol 37: 64A-70A.

de Kruif P. 1926. Microbe hunters. New York, NY: Blue Ribbon Books.

Diamond J. 1997. Guns, germs and steel: The fates of human societies. New York, NY: Random House.

Downing AL, Painter HA, and Knowles G. 1964. Nitrification in the activated-sludge process. J Inst Sew Purif 1964: 130-58.

Gasol JM, Pedrós-Alió C, and Vaqué D. 2002. Regulation of bacterial assemblages in oligotrophic plankton systems: results from experimental and empirical approaches. Anton Leeuw Int J G 81: 435-52.

Gaudy AF and Gaudy ET. 2001. Elements of bioenvironmental engineering. Oxford, UK: Oxford University Press.

Glibert PA. 1998. Interactions of top-down and bottom-up control in planktonic nitrogen cycling. Hydrobiologia 363: 1-12.

Graham DW and Curtis TP. 2003. Ecological theory and bioremediation. In: Head I, Singleton I, and Milner MG (Eds). Bioremediation: a critical review. Wymondham, UK: Horizon Scientific Press.

Howarth R, Anderson D, Cloern J, et al. 2000. Nutrient pollution of coastal rivers, bays, and seas. Issues in Ecology 7 . Washington, DC: Ecological Society of America.

Hubbell SP. 2001. Unified neutral theory of biodiversity and biogeography. Princeton, NJ: Princeton University Press.

Huismann J and Weissing FJ. 1999. Biodiversity of plankton by species oscillations and chaos. Nature 402: 407-08.

Huismann J and Weissing FJ. 2000. Biological conditions for oscillations and chaos generated by multispecies competition. Ecology 82: 2682-95.

ISP (Institute of Sewage Purification). 1954. Symposium on the evolution and development of the activated sludge process of sewage purification in Great Britain. J Proc Inst Sew Pur Part 3: $174-86$.

Kildsgaard J and Engesgaard P. 2001. Numerical analysis of biological clogging in two-dimensional sand box experiments. $J$ Contam Hydrol 50: 261-85.

Krebs CJ. 2001. Ecology, 5th ed. San Francisco, CA: Benjamin Cummings, Addison Wesley Longman, Inc.

Kirchman DA. 2002. Microbial ecology of the oceans. New York, NY: John Wiley and Sons.

Langenheder S and Jürgens K. 2001. Regulation of bacterial biomass and community structure by metazoan and protozoan predation. Limnol Oceanogr 46: 121-34.

Lawrence AW and McCarty PL. 1970. Unified theory for biological treatment design and operation. J Sanit Eng ASCE 96: 757-78.

Lubchenko J, Olson AM, Brubaker LB, et al. 1991. The Sustainable Biosphere Initiative: an ecological research agenda. Ecology 72: 371-412.

MacArthur RH. 1972. Geographical ecology. New York, NY: Harper and Row.

MacArthur RH and EO Wilson. 1966. The theory of island bio- geography. Princeton, NJ: Princeton University Press.

Martin AJ. 1927. The activated sludge process. London, UK: Macdonald and Evans.

McKinney RE. 1962. Microbiology for sanitary engineers. New York, NY: McGraw-Hill.

Metcalf and Eddy, Inc. 2003. Wastewater engineering: treatment and reuse. New York, NY: McGraw-Hill.

Mitsch WJ. 1997. Ecological engineering: the roots and rationale of a new ecological paradigm. In: Etnier C and Guterstam B (Eds). Ecological engineering for wastewater treatment. Boca Raton, FL: Lewis Publishers.

Morin PJ. 1999. Community ecology. Malden, MA: Blackwell Science, Inc.

Purkhold U, Pommerening-Roser A, Juretschko S, et al. 2000. Phylogeny of all recognized species of ammonia oxidizers based on comparative $16 \mathrm{~S}$ rRNA and amo sequence analysis: implications for molecular diversity surveys. Appl Environ Microbiol 66: 5368-82.

Röling WFM, Milner MG, Jones DM, et al. 2002. Robust hydrocarbon degradation and dynamics of bacterial communities during nutrient-enhanced oil spill bioremediation. Appl Environ Microb 68: 5537-48.

Rowan AK, Snape JR, Fearnside D, et al. 2003. Composition and diversity of ammonia-oxidising bacterial communities in wastewater reactors of different design treating identical wastewater. FEMS Microbiol Ecol 41: 195-206.

Saikaly PE and Oerther DB. Bacterial competition in activated sludge: theoretical analysis of varying solids retention times on diversity. Microbial Ecol. In press.

Seviour RJ. 1998. Factors affecting the occurrence of filamentous bacteria in activated sludge plants. In: Seviour RJ and Blackall LL (Eds). The microbiology of activated sludge. London, UK: Chapman and Hall.

Sherr EB and Sherr BF. 2002. Significance of predation by protists in aquatic microbial food webs. Anton Leeuw Int $J$ G 81: 293-308.

Smith VH, Cleland DL, and Graham DW. 1998. Application of resource-ratio theory to hydrocarbon bioremediation. Environ Sci Technol 32: 3386-95.

Sterner RW and Elser JJ. 2002. Ecological stoichiometry: the biology of elements from molecules to the biosphere. Princeton, NJ: Princeton University Press.

Stiling P. 2002. Ecology: theory and applications, 4th ed. Upper Saddle River, NJ: Prentice-Hall.

Thingstad TF, Havskum H, Kaas H, et al. 1999. Bacteria-protist interactions and organic matter degradation under P-limited conditions: analysis of an enclosure experiment using a simple model. Limnol Oceanogr 44: 62-79.

Tilman D. 1982. Resource competition and community structure. Princeton, NJ: Princeton University Press.

Turchin P. 2003. Complex population dynamics: a theoretical/empirical synthesis. Princeton, NJ: Princeton University Press.

Wagner M, Loy A, Noguera R, Purkhold U, et al. 2002. Microbial community composition and function in wastewater treatment plants. Anton Leeuw Int J G 81: 665-80.

Ward BL and Graham DW. 1997. Effects of temperature on the survival of fecal coliform bacteria during aerobic digestion of domestic biosolids. In: Proceedings of the CSCE/ASCE Joint Environmental Engineering Conference. p 247-55.

Welch EB and Lindell T. 1992. Ecological effects of wastewater: applied limnology and pollutant effects, 2nd ed. New York, NY: Chapman and Hall.

Wheeler M. 1995. Ruskin and environment. Manchester, UK: Manchester University Press. 